\title{
A CONFIABILIDADE DOS PRODUTORES RURAIS DO SEMIÁRIDO BAIANO NAS PREVISÕES METEOROLÓGICAS OBTIDAS ATRAVÉS DA TELEVISÃO
}

\author{
$\underline{\text { Natália de Brito Lima }}{ }^{1}$; Elane Fiuza Borges ${ }^{2}$; Manuel Cabalar Fuentes ${ }^{3}$ \\ 1. Bolsista PROBIC/UEFS, Graduando em Bacharelado em Geografia, Universidade Estadual de Feira de Santana, e-mail: \\ natalia_lima97@hotmail.com \\ 2. Orientadora, Departamento de Ciências Humanas e Filosofia, Universidade Estadual de Feira de Santana, e-mail: \\ elaneborges@gmail.com \\ 3. Coordenador do Projeto "A rede meteorológica da Bahia e sua adequação para o planejamento da Produção agrícola", \\ Departamento de Ciências Humanas e Filosofia, Universidade Estadual de Feira de Santana, e-mail: \\ $\underline{\text { manuel.cabalar@gmail.com }}$
}

PALAVRAS-CHAVE: Previsão Meteorológica; Televisão; Produtores Rurais.

\section{INTRODUÇÃO}

O domínio climático semiárido ocupa um total de $86 \%$ do território brasileiro (MARENGO, 2008) e o estado da Bahia apresenta cerca de $70 \%$ de sua área sob este domínio (Projeto Áridas/CAR. AOUAD,1995). O que mais caracteriza este domínio é a irregularidade na distribuição das chuvas, com forte sazonalidade e incidência de secas persistentes; índices de aridez acentuados - entre o árido $(0,05$ a 0,20$)$ e o semiárido $(0,21$ a 0,50); predomínio de depressões pedi planadas com solos pouco desenvolvidos, por vezes rochosos ou pedregosos, recobertos por caatingas arbóreo- arbustivas (AB'SABER, 1970, 1974, 1977, 2003).

Mesmo com todo o desenvolvimento técnico-científico que a atual sociedade detém, o clima e as condições atmosféricas ainda se constituem como as principais variáveis para a agricultura, influenciando em todos os estágios da cadeia produtiva, que vai desde a preparação da terra, passando pela semeadura, crescimento dos cultivos, colheita, armazenagem, transporte, até a comercialização. Mais concretamente, os elementos climáticos que influenciam na agricultura são: radiação solar, temperatura, umidade e vento, os mesmos que influenciam na vegetação de modo geral (AYOADE, 2010).

As condições climáticas do semiárido baiano normalmente não são favoráveis à agropecuária, dada à baixa fertilidade dos solos e escassez hídrica. A produção, neste caso, se torna viável a partir de um planejamento e organização das atividades agropecuárias a serem exercidas. Neste contexto, as informações sobre o tempo e o clima são de suma importância para as atividades agropecuárias. A TV, como principal e mais acessível meio de comunicação em massa no Brasil atualmente, exerce grande função neste quesito, pois, a partir deste veículo muitos produtores rurais obtêm informações sobre as condições meteorológicas atuais e também à curto prazo.

A televisão no Brasil em 1960 (CAMPANELLA, 2011) foi se tornando um meio de comunicação em massa cada vez mais importante. De acordo com a Pesquisa Brasileira de Mídia realizada no ano de 2015, 95\% dos brasileiros assistem TV regularmente e $74 \%$ a veem todos os dias. Segundo a Pesquisa Nacional por Amostra de Domicílios (PNAD) realizada em 2013, no ano dito o País tinha 65,1 milhões de domicílios particulares permanentes, dos quais, 63,3 milhões $(97,2 \%)$ possuíam televisão.

Compreendendo a importância da televisão para $o$ acesso às informações meteorológicas/climáticas, o trabalho realizado aqui visou averiguar a confiabilidade dos produtores rurais do semiárido baiano nestas informações. Para isso, foi aplicado um total de 100 questionários nos municípios de Retirolândia, Valente e São Domingos (recorte espacial dá área. Figura 1) aos produtores rurais. O questionário é composto por 36 questões porque este é parte de um projeto maior, mas como o principal objetivo da presente pesquisa é observar se a informação meteorológica fornecida pela televisão através dos telejornais é 
confiável para os produtores rurais do semiárido baiano, só foram utilizadas nove questões (da questão 12 a 20), questões essas referentes à utilização da televisão para obtenção de informações climáticas/meteorológicas.

\section{MATERIAL E MÉTODOS OU METODOLOGIA (ou equivalente)}

Localizados no Território de Identidade do Sisal, os municípios de Retirolândia, Valente e São Domingos (Figura 1) apresentam domínio climático semiárido. As cidades de Retirolândia, Valente e São Domingos, de acordo com o IBGE, são consideradas cidades pequenas, pois possuem um número de habitantes inferior à 100.00. Retirolândia possui uma população estimada de 13.319 habitantes, Valente 27.906 habitantes e São Domingos 9.877 habitantes (IBGE, 2015).

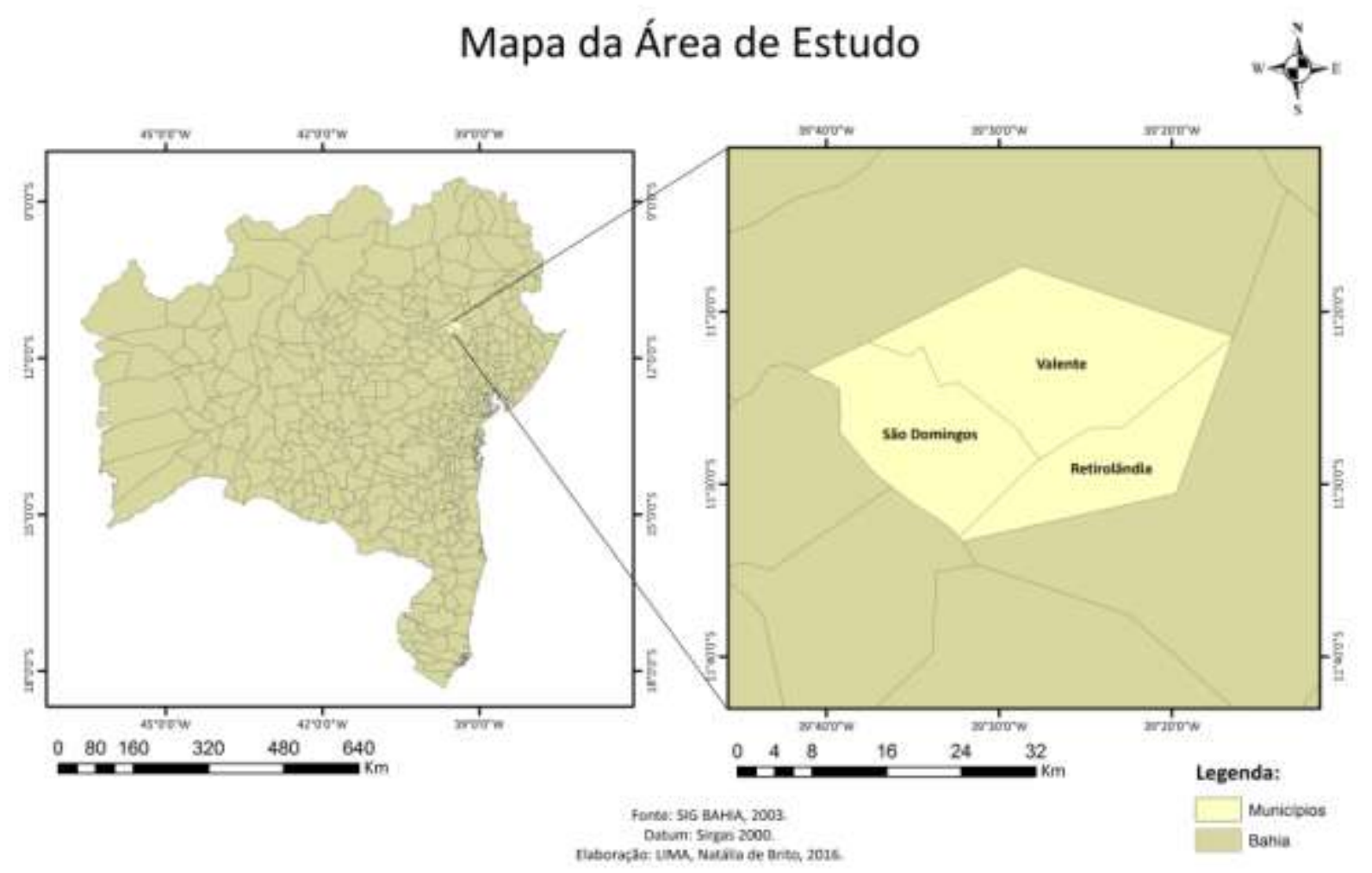

Figura 1: Mapa de localização dos municípios de Retirolândia, São Domingos e Valente.

Para a estruturação e realização do presente trabalho, de início, partiu-se da construção de um arcabouço teórico-conceitual abrangendo os principais temas que foram abordados durante a realização da pesquisa: informações meteorológicas/climáticas, a televisão como meio de comunicação no Brasil, produção agrícola e a comunicação na Meteorologia. Após esta discussão teórica-conceitual, foram realizados dois trabalhos de campo nos municípios de Retirolândia, Valente e São Domingos. No primeiro trabalho de campo foram aplicados um total de 69 questionários aos produtores rurais dos municípios aqui já citados. Na segunda saída de campo, que foi realizada no dia 14/11/2015, foram aplicados 31 questionários, atingindo assim a meta da pesquisa que era a aplicação de 100 questionários.

O questionário aplicado era composto por 36 questões porque este é parte de um projeto maior, mas como o principal objetivo da presente pesquisa é observar se a informação meteorológica fornecida pela televisão através dos telejornais é confiável para os produtores rurais dos municípios de Retirolândia, São Domingos e Valente, só foram utilizadas nove questões (da questão 12 a 20), questões essas referentes à utilização da televisão para 
obtenção de informações climáticas/meteorológicas. Sendo assim, esses dados foram tabulados e serão discutidos aqui.

\section{RESULTADOS E/OU DISCUSSÃO (ou Análise e discussão dos resultados)}

Como o foco da presente pesquisa foi o acompanhamento da previsão do tempo pela televisão, só foram analisados os dados dos $90,78 \%$ de agricultores que faziam este acompanhamento por meio da mesma. Questionamos à eles se achavam confiáveis as informações sobre o tempo que adquiriam pela TV, 46,37\% dos agricultores entrevistados afirmaram sim, que são confiáveis essa informações. Em contrapartida, 39,13\% dos agricultores disseram não, alegando não confiar nestas informações e 10 têm desconfiança da veracidade destas informações.

Em seguida, perguntamos o motivo de confiar e de não confiar. As justificativas dos que alegaram não confiar nas informações foram quase as mesmas. Alegaram que não confiam pelo fato da previsão mostrar que irá chover e a chuva não vir ou por simplesmente acreditar que o homem não pode prever a chuva, só quem é capaz de saber sobre o tempo é "Deus". Os que disseram confiar deram diversas justificativas, dentre elas que a previsão sempre dá certo, que era confiável por ser uma ciência ou que os meteorologistas estudaram e sabem o que estão dizendo. Entretanto, alguns alegaram confiar mais em Deus ou que a transmissão dessas informações fica a desejar porque a Bahia é muito grande e não dá para se ter uma previsão tão precisa para todo o estado. De nada vale a produção das informações meteorológicas sem que estas cheguem aos seus interlocutores de forma clara, assim não podendo fazer aplicações para tais. Sendo assim, posteriormente, o que foi posto em questão aos pequenos produtores rurais do semiárido baiano foi o entendimento das previsões climáticas/meteorológicas. Dentre os 69 produtores rurais entrevistados, 71,01\% alegaram entender de forma clara o que era dito nos telejornais sobre as informações do tempo. $23,18 \%$ dos agricultores afirmaram não entender e 5,79\% dos agricultores disseram que entendiam parcialmente. Após isso, perguntamos o motivo de entenderem ou não entenderem. Dentre os que afirmaram entender de forma clara o que era dito nas previsões meteorológicas, $55,10 \%$ deles não quiseram justificar o porquê de entenderem, o que não é tão positivo para avaliarmos com maior veracidade sobre o entendimento deles. Os que justificaram, disseram que entendem porque falam bonito, que falam de forma simples, que alguma outra pessoa por perto explica ou porque fica claro e dá para entender. Alguns entrevistados, mesmo afirmando entender, na justificativa demonstraram que as informações não ficam tão claras para eles entenderem. Já entre os que relataram não entender muito bem as informações climáticas/meteorológicas passadas pelos telejornais, foram dadas justificativas quase que idênticas sobre o motivo de não entenderem. Afirmaram que o motivo disto é a linguagem utilizada pelos meteorologistas ao passar as informações, pois é de difícil entendimento, que falam muito "difícil". Os agricultores que disseram entender parcialmente, explicaram que o motivo é que os mapas confundem ou que as coisas de Deus são difíceis de entender. A utilização de termos técnicos pelos meteorologistas nos telejornais muitas das vezes acaba dificultando o entendimento para diversas pessoas.

No que se refere à utilização da informação do tempo para o trabalho dos agricultores, 22 dos produtores rurais entrevistados afirmaram não fazer uso destas informações para aplicar em seus trabalhos. Todavia, 47 dos entrevistados disseram que utilizavam as informações meteorológicas nos seus trabalhos. Ao perguntarmos aos que utilizavam estas informações como faziam o uso delas, alguns não responderam, porém, os que responderam explicaram que utilizavam estas informações para fazer o planejamento do plantio, financeiro e de criação de animais.

Ao final, foi posto em questão o que deveria ser melhorado na transmissão da previsão do tempo. Infelizmente, $36,23 \%$ (25 agricultores) dos entrevistados que acompanhavam a 
previsão do tempo pela televisão não quiseram responder como poderia haver uma melhora na transmissão da previsão meteorológica. Entretanto, os demais responderam e deram ótimas sugestões, dentre elas: previsões mais precisas da região semiárida baiana, explicar de forma "melhor" para que tudo fique mais claro, instalação de equipamentos climatológicos pela região e melhorias na linguagem utilizada (utilização de menos termos técnicos).

\section{CONSIDERAÇÕES FINAIS (ou Conclusão)}

Com a execução da presente pesquisa, foi perceptível que a grande maioria dos produtores rurais do semiárido baiano que acompanham a previsão do tempo utiliza a televisão como principal fonte, isso é decorrido da sua grande facilidade de acesso. Como foi exposto aqui, no semiárido do estado da Bahia as condições climáticas não são nada favoráveis às atividades agropecuárias, sendo assim, para que os produtores rurais possam realizar as suas atividades, eles necessitam anteriormente fazer todo um planejamento para que não tenha prejuízos. Desta forma, para que os agricultores possam fazer uso das informações transmitidas pela televisão, é indispensável que estas cheguem até eles de forma sucinta, o que não ocorre. Apesar de maior parte dos entrevistados afirmarem que entendem de forma clara as informações do tempo que são obtidas pelo meio televisivo, nas justificativas ficou explícito que estas informações não são passadas de forma tão cognoscível assim, talvez seja devido ao uso de termos técnicos, o que acaba deixando esta passagem de informação ineficaz. Pois uma vez que não se compreende direito, não poderá ser utilizada da maneira devida. Há também uma grande desconfiança por parte dos agricultores para com a precisão meteorológica, isso decorre pelo fato de muitas vezes darem informações "erradas" nos telejornais. Os produtores rurais julgam como errada, pois nas cidades em que residem realmente não ocorre como dizem na previsão do tempo, mas isto acontece pelo fato de a Bahia ter uma grande extensão territorial, para que se tenham informações mais precisas, talvez seja necessária a implantação de mais estações meteorológicas no semiárido baiano.

\section{REFERÊNCIAS}

AB'SABER, Aziz Nacib. Províncias geológicas e domínios morfoclimáticos no Brasil. Geomorfologia, n.20, 1970.

AB'SABER, Aziz Nacib. O domínio morfoclimático semi-árido das caatingas brasileiras. Geomorfologia, n. 43. 1974.

AB'SABER, Aziz Nacib. Problemática da desertificação e da savanização no Brasil intertropical. São Paulo: Instituto de Geografia da USP. Geomorfologia, 53. 1977.

AB'SABER, Aziz Nacib. Os Domínios de natureza no Brasil - Potencialidades Paisagísticas. São Paulo Ateliê Editorial. 2003.

AOUAD, Marilene dos Santos. Desertificação. Salvador, CAR - Projeto Áridas Bahia, 1995.

AYOADE, J. O. Introdução à climatologia para os trópicos. $13^{\mathrm{a}}$ Ed. - Rio de Janeiro: Bertrande Brasil, 2010.

CAMPANELLA, Bruno. A TV no Brasil: seis décadas e muitas histórias. jan./jun. 2011; No2: p. 253-259.

IBGE - Instituto Brasileiro de Geografia e Estatística. Pesquisa Nacional por Amostra de Domicílios: Acesso à Internet e à Televisão e Posse de Telefone Móvel Celular para uso Pessoal - 2013. Rio de Janeiro: IBGE, 2015.

MARENGO, Jose A. Vulnerabilidade, impactos e adaptação à mudança do clima no semiárido do Brasil. BRASÍLIA,DF: PARCERIAS ESTRATÉGICAS, 2008. 